\title{
Analysis of IT Service Management of Salatigaku Application using Information Techonology Infrastructure Library (ITIL) V3 Framework
}

\author{
Meylinda Ayu Pratiwi ${ }^{1}$, Andeka Rocky Tanaamah ${ }^{2}$ \\ 1,2Information System Department, Satya Wacana Christian University, Salatiga, Indonesia \\ Email:1682015085@student.uksw.edu, ${ }^{2}$ atanaamah@uksw.edu
}

\begin{abstract}
IT service management is very necessary in improving the quality of the IT service in order to make a business runs smoothly with the organizational purposes. Here, an application called "SALATIGAKU" which is developed by DISKOMINFO has been good enough. However, there are still some obstacle in applying the application in real time. The lack of human resources who are able to handle every problem in IT field still become one of the problems the DISKOMINFO is struggling with. In addition, the lack of routines in data backup saving can lead to corporate data leakage. This study is using ITIL V3 domain service operation framework which focus on the business operational activities. The result of this study, some recommendation are showed such as increasing the amount of human resources who is expert in IT. Therefore, every obstacle that come up in the application can be overcome quickly without disturbing other activities. Other recommendation, an SOP (Standard Operating Procedure) should be provided in backup data related with the valuable archive such as data files. Hopefully, by doing this research, DISKOMINFO can reduce the obstacles so that "SALATIGAKU" can work optimally. Thus, the effectiveness and the efficiency of the organization's business performance will be improved.
\end{abstract}

Keywords: IT service management, IT service quality, ITIL V3.

\section{PENDAHULUAN}

Semakin hari perkembangan Teknologi Informasi (TI) berkembang sangat pesat.Kini peranan TI sudah menjadiprioritas utama dalam menunjang keberhasilan bisnis, salah satunya adalah layanan TI.Dalam meningkatkan efektivitas dan efisiensi yang berpengaruh terhadap kepuasaan pelanggan, maka perlu adanya layanan TI dengan kualitas baik.Sehingga manajemen layanan TI 
sangat penting bagi organisasi dalam mengoptimalkan layanan TI untuk memenuhi kebutuhan bisnis dan mengelola infrastruktur TI serta menyelaraskan TI dengan tujuan organisasi [1].Manajemen layanan TI merupakan alat untuk membantu dalam menunjang keberhasilan bisnis organisasi., sehingga didefinisikan sebagai pendekatan untuk operasi TI yang berfokus pada pada layanan TI, pelanggan, perjanjian tingkat layanan, dan penanganan fungsi TI melalui proses kegiatan sehari - hari [2].

Saat ini penggunaan TI untuk meningkatkan hasil kinerja layanan tidak hanya diterapkan pada perusahaan - perusahaan swasta saja, tetapi sudah merambah ke instansi pemerintahan.Dimana instansi pemerintahan juga melibatkan TI dalam mewujudkan layanan masyarakat, salah satunya adalah Dinas Komunikasi dan Informatika (DISKOMINFO).DISKOMINFO merupakan instansi pemerintahan yang bertanggung jawab sebagai pengelola dan pelayanan informasi di lingkungan pemerintahan Salatiga, dalam mewujudkan pelayanan informasi kepada seluruh masyarakat Kota Salatiga maupun kepada publik secara umum. Berdasarkan Peraturan Walikota Salatiga No. 38 Tahun 2016 tentang Kedudukan, Susunan Organisasi, Tugas dan Fungsi serta Tata Kerja Dinas Komunikasi dan Informatika, Dinas Kominfo Kota Salatiga mempunyai tugas membantu Walikota melaksanakan urusan Pemerintahan yang menjadi kewenangan Daerah bidang komunikasi dan informatika, bidang statistik dan bidang persandian serta tugas pembantuan yang diberikan kepada Daerah [3]. Dalam menjalankan tugasnya sebagai penyedia layanan, DISKOMINFO memanfaatkan TI untuk mendukung kinerja operasional bisnis.

Salah satu layanan yang diberikan DISKOMINFO untuk masyarakat Kota Salatiga adalah aplikasi Salatigaku. Salatigaku merupakan aplikasi yang berisi tentang informasi OPD (Organisasi Perangkat Daerah) yang ada di Kota Salatiga, Salatigaku dibangun oleh pihak ketiga yang sudah berjalan sejak 2018. Aplikasi ini merupakan aplikasi berbasis mobile yang dapat di download secara gratis oleh seluruh masyarakat baik dari Salatiga maupun diluar Salatiga, fungsinya untuk mengumpulkan berbagai macam aplikasi yang ada di Salatiga kemudian digabungkan menjadi satu wadah agar dapat diakses secara mudah.

Adapun tujuan dibangunnya Salatigaku adalah untuk mendekatkan akses informasi kemasyarakatan Kota Salatiga, sehingga diharapkan dengan adanya aplikasi ini masyakarat dengan mudah dan cepat mendapatkan informasi umum seputar Salatiga. Sebagai aplikasi baru Salatigaku tentu tidak lepas dari kata sempurna, hal ini terlihat dari beberapa masalah yang pernah dihadapi diantaranya terdapat beberapa menu yang tidak dapat diakses sesuai kebutuhan.Dimana yang seharusnya menu tersebut dapat menampilkan data - 
data sesuai dengan perintah yang terdapat di menu aplikasi, namun pada kenyataannya menu tersebut tidak berjalan dan menyebabkan kepuasan user menjadi berkurang.Kemudian kurangnya SDM yang memumpuni di bidang TI juga menjadi salah satu masalah yang dihadapi. Seperti halnya bila terjadi permasalahan yang tidak dapat di bandle oleh operator maka, untuk mengatasi permasalahan tersebut pihak DISKOMINFO menyerahkannya kepada pihak ketiga. Hal ini dapat menghambat kinerja layanan TI organisasi, karena masalah yang timbul tidak dapat langsung ditangani sehingga membutuhkan waktu yang cukup panjang untuk mengatasi masalah tersebut.

Berdasarkan permasalahan diatas, maka penelitian ini bertujuan untuk melakukan analisis manajemen layanan TI di DISKOMINFO Kota Salatiga yang berfokus pada aplikasi Salataigaku, dengan mengadopsi framework Information Tecbnology Infrastructure Library (ITIL) V3 domain service operation. ITIL dipilih karena merupakan sebuah framework yang berisi best practice yang dapat digunakan untuk membantu organisasi dalam mengembangkan proses Information Technology Service Management (ITSM) [4]. ITIL menyediakan kerangka kerja bagi tata kelola TI, 'membungkus layanan', dan berfokus pada pengukuran terus-menerus dan perbaikan kualitas layanan TI yang diberikan, baik dari sisi bisnis dan perspektif pelanggan [4].Penelitian ini hanya berfokus pada Domain Service Operation, karena domain tersebut mencakup seluruh kegiatan operasional harian pengelolaan layanan TI yang terdapat panduan bagaimana mengelola layanan TI yang baik [5].Sehingga diharapkan dengan adanya penelitian ini dapat mengetahui sejauh mana implementasi layanan Salatigaku diterapkan. Adapun hasil temuan akan diberikan rekomendasi untuk meningkatkan layanan TI agar dapat berjalan selaras dengan tujuan organisasi.

\section{METODE PENELITIAN}

\subsection{Metode Pengumpulan Data}

Penelitian ini dilakukan pada layanan aplikasi Salatigaku yang dikelola oleh DISKOMINFO Salatiga.Tujuan dari penelitian ini untuk melihat kondisi dari aplikasi Salatigaku, apakah aplikasi yang disediakan untuk membantu masyarakat dalam mendapatkan informasi umum terkait Kota Salatiga sudah berjalan sesuai dengan kebutuhan organisasi.Metode yang digunakan dalam penelitian ini adalah metode kualitatif dengan melakukan wawancara kepada narasumber terkait layanan aplikasi Salatigaku serta melakukan observasi dengan melihat kondisi layanan secara langsung dan mengumpulkan dokumen - dokumen sesuai kebutuhan. Wawancara dilakukan selama 2 hari bersama dua narasumber diantaranya Bapak Andy sebagai Kepala Seksi Layanan Data Informasi selaku pengguna aplikasi Salatigaku dan Bapak Budi di bidang Aplikasi dan Informatika 
Vol. 2, No. 1, March 2020

p-ISSN: 2656-5935 http://journal-isi.org/index.php/isi e-ISSN: 2656-4882

(APTIKA) selaku pranata komputer. Dalam melakukan wawancara, ITIL digunakan sebagai standar dalam mendukung berjalannya penelitian.Dengan memanfaatkan ITIL sebagai kerangka kerja best practice, maka dapat membantu membantu organisasi dalam mengembangkan proses ITSM, yang berupa panduan untuk menetapkan proses - proses umum, peran dan aktivitas proses bisnis [6].

\subsection{Tahapan Penelitian}

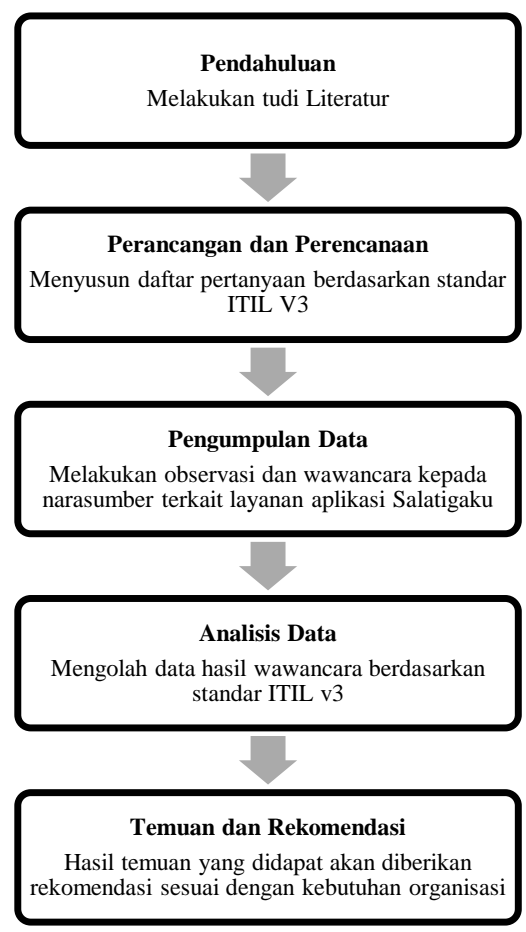

Gambar 1. Tahapan Penelitian

Tahapan pertama yang dilakukan adalah pendahuluan.Tahapan ini dilakukan sebelum penelitian dimulai dengan menganalisis permasalahan yang dihadapi DISKOMINFO pada layanan aplikasi Salatigaku.Kemudian didukung dengan studi literatur, studi literatur dilaksanakan dengan mempelajari dan memahami penelitian terdahulu guna mendapat gambaran terkait topik pembahasan yaitu analisis manajemen layanan TI dengan menggunakan pendekatan Information Techonology Infrastructure Library (ITIL) v3 pada domain 
Service Operation.Tahapan kedua adalah perencaaan dan perancangan. Menyusun daftar pertanyaan disusun berdasarkan panduan dari domain service operation yang terdiri dari lima sub domain, diantaranya event management, incident management, problem management, request fullfilment, dan access management sesuai dengan standar ITIL V3. Setelah membuat daftar pertanyaan, dilanjutkan dengan membuat jadwal untuk melakukan wawancara dengan narasumber.

Tahapan ketiga yaitu proses pengumpulan data, proses ini dilakukan dengan metode kualitatif. Dalam mendukung penelitian ini, wawancara dilakukan dengan narasumber terkait layanan aplikasi Salatigaku yang dibantu menggunakan alat bantu perekam suara untuk mendukung proses berjalannya kegiatan dan dilakukan observasi untuk melihat kondisi layanan secara langsung. Apabila dalam pengumpulan data masih membutuhkan data tambahan, maka dapat dilakukan kembali proses tahapan penelitian dari awal. Tahapan selanjutnya adalah menganalisi data. Data yang sudah terkumpul dari hasil wawancara dan observasi dapat diolah dengan menggunakan framework ITIL V3 service operation untuk menganalisi permasalahan yang dihadapi serta cara penanganan dari setiap permasalahan. Dari hasil yang didapat setelah data diolah yaitu dengan mendapat beberapa temuan, dimana temuan tersebut merupakan kelemahan atau kekurangan yang sedang dihadapi oleh DISKOMINFO dalam mengimplementasikan layanan aplikasi Salatigaku.Sehingga tahapan terakhir dari penelitian ini yaitu dengan mendapatkan temuan dan memberikan rekomendasi terkait temuan yang dihadapi.Sehingga diharapkan dengan adanya rekomendasi ini, dapat memperbaiki kinerja bisnis serta meningkatkan efektifitas dan efisiensi layanan.

\section{HASIL DAN PEMBAHASAN}

Salatigaku merupakan aplikasi yang disediakan oleh PEMKOT (Pemerintah Kota) dan kemudian dikelola oleh DISKOMINFO untuk mempermudah masyarakat dalam mendapatkan informasi terkait Kota Salatiga. Aplikasi yang baru berjalan pada tahun 2018 ini memiliki konsep meminimalisir operator dengan menggunakan metode pengambilan data secara otomatis atau yang biasa disebut grapping dari website - website OPD, sehingga tidak memerlukan peran manusia sebagai operator untuk menuliskan berita secara manual. Tujuan dibangunnya aplikasi Salatigaku adalah untuk mendekatkan akses informasi kemasyarakatan Kota Salatiga.Dengan melalui satu media saja, masyarakat bisa mendapatkan berbagai macam informasi terkait statistik, akomodasi, kuliner serta pelayanan online yang terdapat di Kota Salatiga.Sejauh ini aplikasi Salatigaku 
sudah cukup membantu masyarakat dalam memberikan informasi.Tidak banyak masyarakat yang memberikan kritik tentang aplikasi Salatigaku, namun lebih banyak masyarakat yang memberikan masukan dan mengharapkan agar aplikasi tersebut dapat ditingkatkan lagi dengan menambahkan beberapa fitur agar aplikasi Salatigaku jauh lebih menarik user dalam menggunakan aplikasi tersebut.

\section{Event Management}

Event Management adalah merupakan manajemen untuk memonitor, mensurvei serta mengevaluasi semua peristiwa yang terjadi dalam infrastruktur TI untuk meninjau kinerja TI secara berkala guna melacak dan meningkatkan persiapan dalam menghadapi kejadian yang tidak terduga [7]. Sejauh ini DISKOMINFO telah melakukan monitoring aplikasi yang dilakukan selama sebulan sekali, berikut yang disampaikan oleh bapak Andy "monitoring sendiri ada rapat oleh tim pengelola yang dilaksanakan sebulan sekali, itu rapat monev pengelola layanan informasi daerah, di dalamnya sudah termasuk pengelolaan aplikasi Salatigaku". Berdasarkan pernyataan tersebut dapat disimpulkan bahwa pihak DISKOMINFO telah menerapkan event management dengan melakukan memonitoring layanan. Dengan adanya monitoring secara rutin setiap peristiwa dapat dievaluasi dan kemungkinan - kemungkinan yang akan terjadi dapat dicegah.

\section{Incident Management}

Incident Management adalah proses melakukan pemulihan atau pembenahan pada layanan yang mengalami kerusakan. Tujuan dari incident management adalah untuk mengembalikan layanan kembali normal secepat mungkin, dan untuk meminimalkan dampak merugikan pada operasi bisnis [4].Berdasarkan wawancara yang dilakukan dengan bapak Andy "kemarin baru saja diserang hacker, sampai nggak bisa diakses beberapa hari. Jadikan ada dua sistem ya.aplikeasi android terus datanya ngambil dari server, lha jika terjadi serangan kan yang diserang server disini jadi otomatis aplikeasinya nggak bisa narik data dari server jadinya error". Menurut pernyataan dari bapak Andy adanya serangan dari hacker tentu sangat menghambat kinerja layanan aplikasi, yang menyebabkan aplikasi tidak dapat diakses dalam beberapa waktu. Mengatasi hal tersebut dari pihak userakan menyerahkan masalah tersebut ke bidang APTIKA (Aplikasi dan Teknologi), agar permasalahan segera ditangani. Berikut penjelasan yang disampaikan oleh bapak Budi “mengatasinya dengan jaringan dulu, jadi misalnya kalo hacker itu kan menyerangnya masuknya lewat jaringan internet itu kan bisa, kadang tempat kami mas Andri itu yang ngurusi jaringan sudah ditutup dulu beberapa port itu sudah kami matikan. Tapi kalau dari segi aplikasi kan 
eee..itu kan kami juga apa yaa nggak bisa utak atik. karena kan ada kerjasama dengan pibak ketiga, tapi kita antisipasi dengan backup jadi kalau ada serangan yaa nggak. bisa dikembalikan normal jadi dikembalikan ke backup terakbir". Berdasarkan jawaban tersebut, pada bagian APTIKA sudah melakukan backup untuk mengantisipasi kehilangan data, namun backup belum sepenuhnya dilakukan secara rutin dikarenakan belum memiliki Standar Operasional Prosedur (SOP) yang dibuat terkait arsip data.

Selain itu sebagai penyedia layanan DISKOMINFO belum memiliki Service Level Agreement (SLA) yang berfungsi sebagai surat perjanjian antara penyedia dan pengguna layanan sebagai jaminan untuk tingkat layanan yang disepakati. Sehingga untuk pengajuan sebuah permintaan, customer harus melalui prosedur seperti yang disampaikan dimana oleh bapak Budi "jadi kalo mau buat aplikasi harus ada surat rekomendasi resmi dari DISKOMINFO, jika nggake ada surat rekomendasi itu, dari pibak BAPPED A nggak bisa membukakan anggaran untuk aplikasi yang akan dirancang".

\section{Problem Management}

Problem Management adalah tahapan analisis untuk mengatasi masalah yang terjadi dan mencari penyebabnya agar masalah tidak terulang di masa yang akan datang. Salatigaku termasuk aplikasi yang baru setahun dijalankan, sehingga memungkinkan aplikasi tersebut masih terdapat beberapa kendala. Menurut hasil wawancara yang dilakukan dengan bapak Andy "emm,, memang ada beberapa menu yang nggak jalan jadi cukup mengganggu sib itu. Misalnya apa yaa yang kemarin itu? Informasi pelayanan publik kayaknya yang masib belum jalan".Dilihat dari pernyataan tersebut dapat disimpulkan bahwa Salatigaku masih belum berjalan sesuai dengan kebutuhan, karena masih terdapat beberapa menu yang tidak dapat diakses.Hal ini tentu dapat mengganggu kinerja layanan operasional bisnis.Dalam menangani insiden tersebut pihak DISKOMINFO menyerahkannya kepada pihak ketiga agar insiden tersebut dapat segera ditangani dan aplikasi bisa tetap berjalan "untuk saat ini semua masih pibak ketiga karena kita belum punya tenaga seng mampu untuk mengembangkan itu, abli di coding android masib belum ada disini".Dari pernyataan tersebut dapat disimpulkan bahwa setiap permasalahan yang terjadi tidak sepenuhnya dapat ditangani sendiri oleh pihak DISKOMINFO. Selain karena masih terikat kontrak kerjasama dengan pihak ketiga, faktor lain yang mendukung adalah kurangnya sumber daya manusia (SDM) yang memadahi sehingga belum mampu mengani setiap permasalahan yang terjadi dan membutuhkan waktu yang lama menyelesaikan insiden. Dan DISKOMINFO belum memiliki dokumentasi untuk setiap permasalahan yang pernah dialami 
oleh user.Pentingnya pendokumentasian ini agar masalah - masalah yang pernah terjadi dapat tercatat dengan rapi bila sewaktu - waktu masalah yang sama terjadi dapat diketahui penyebab dan penyelesaiannya.

Adapun masalah lain yang dialami mengenai informasi yang ditampilkan pada aplikasi. Menurut pendapat bapak Andy sebagai user, beliau mengatakan bahwa "kita masih bingung karena yang ditampilkan itu kan berita - beritanya masih berita - berita seputar pemerintahan kan itu grapping dari beritanya websitenya OPD OPD sementara berita apa ya, berita peristiwa penting di Salatiga banyak yang tidak termuat di website OPD". Pengambilan data pada aplikasi Salatigaku menggunakan sistem grapping dimana data secara otomatis diambil dari website OPD, sehingga yang ditampilkan pada aplikasi hanya berita - berita seputar pemerintahan saja.Sedangkan menurut bapak Andy, pengunjung aplikasi biasanya lebih tertarik dengan berita atau peristiwa sehari - hari dibandingan berita - berita OPD.Berdasarkan permasalahan diatas dapat disimpulkan bahwa DISKOMINFO belum sepenuhnya dalam menerapkan problem management untuk mengelola layanan.Masih terdapat masalah yang belum dapat terselesaikan. Hal ini bila dibiarkan maka, akan mengurangi tingkat kualitas layanan.

\section{Request Fulfilment}

Request Fulfilment adalah proses permintaan layanan sesuai dengan kebutuhan user. Tujuan dari Pemenuhan Permintaan adalah untuk memungkinkan pengguna meminta dan menerima standar layanan, untuk sumber dan memberikan layanan ini, untuk memberikan informasi kepada pengguna dan pelanggan tentang layanan dan prosedur untuk mendapatkan mereka, dan untuk membantu dengan informasi umum, keluhan dan komentar [4]. Berdasarkan wawancara yang disampaikan oleh bapak Andy "kalo complain ndak, tapi kalo masukan banyak. Jadi kalo setiap ketemu orang gitu ya,, terus membahas Salatigaku gitu mesti mbok ditambabin ini, ditambabin ini banyak sekali, ditambabin menu ini, informasi ini yaa itu kan kita tamping dulu karena ndak semua bisa kita kerjakan to. Karena berbubungan kontrak.juga dengan pibak. ketiga, karena belum kita kembangkan sendir" dari jawaban yang disampaikan dapat disimpulkan bahwa pihak DISKOMINFO telah menerapkan tahapan request fulfillment, walaupun belum sepenuhnya hal ini disebabkan masih terikat kontrak dengan pihak ketiga yang mengharuskan setiap permintaan tidak dapat langsung dikerjakan.

\section{Access Management}

Access Manajement adalah proses pemberian hak akses kepada pengguna layanan agar layanan tidak disalah gunakan oleh pihak - pihak yang tidak berwenang. Dalam pembagian hak akses pada Salatigaku masih dibebankan pada satu admin saja, berikut penuturan dari bapak Andy "pembagian hak akses 
Vol. 2, No. 1, March 2020

p-ISSN: 2656-5935 http://journal-isi.org/index.php/isi

e-ISSN: 2656-4882

sebenamya ada, jadi kayak misalnya tentang pariwisata hanya bisa diisi oleh admin pariwisata terus eee,, informasi tentang rute jalan disitu ada yang ngisi admin dari dinas perbubungan, tetapi sekarang semua baru di bandle satu admin, jadi konsepnya sudah dibangun seperti itu tetapi pelaksanaannya belum". Berdasarkan jawaban yang beliau sampaikan, DISKOMINFO sudah menerapkan access management pada aplikasi Salatigaku.Namun pada kenyataannya masih belum diimplementasikan ke layanan tersebut.

\subsection{Hasil Temuan dan Rekomendasi}

Tabel 1.Hasil Temuan dan Rekomendasi

\begin{tabular}{|c|c|c|c|}
\hline No. & Proses & Temuan & Rekomendasi \\
\hline \multirow[t]{2}{*}{1.} & $\begin{array}{l}\text { Incident } \\
\text { Management }\end{array}$ & $\begin{array}{l}\text { DISKOMINFO belum } \\
\text { memiliki SOP untuk } \\
\text { melakukan backup data } \\
\text { secara rutin. }\end{array}$ & $\begin{array}{l}\text { Dengan menyediakan standar } \\
\text { yang lebih terperinci perihal } \\
\text { backup data. Agar backup } \\
\text { data bisa dilaksanakan secara } \\
\text { rutin untuk menghindari } \\
\text { kehilangan data sewaktu - } \\
\text { waktu. }\end{array}$ \\
\hline & & $\begin{array}{lll}\text { DISKOMINFO } & \text { belum } \\
\text { memiliki SLA } & \text { sebagai } \\
\text { kontrak kerja } & \text { dengan } \\
\text { pihak customer. } & \end{array}$ & $\begin{array}{l}\text { Menyedikan SLA agar } \\
\text { customer yang ingin } \\
\text { bekerjasama mendapatkan } \\
\text { jaminan tingkat pelayanan } \\
\text { yang diharapkan. }\end{array}$ \\
\hline 2. & $\begin{array}{l}\text { Problem } \\
\text { Management }\end{array}$ & 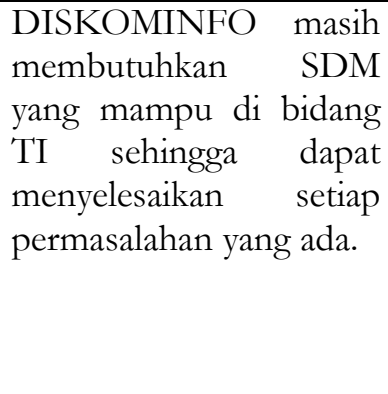 & 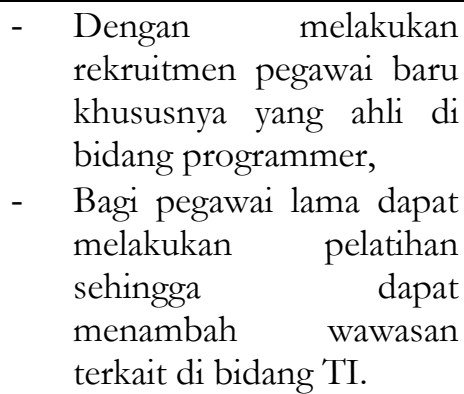 \\
\hline & & $\begin{array}{l}\text { DISKOMINFO belum } \\
\text { memiliki } \\
\text { pendokumentasi untuk } \\
\text { setiap permasalahan } \\
\text { yang pernah terjadi } \\
\text { untuk menghindari } \\
\text { insiden berulang. }\end{array}$ & $\begin{array}{l}\text { Membuat dokumentasi secara } \\
\text { terstruktur terkait masalah - } \\
\text { masalah yang sering terjadi } \\
\text { dan mencatat solusi dari } \\
\text { setiap permasalahan. }\end{array}$ \\
\hline 3. & $\begin{array}{l}\text { Access } \\
\text { Management }\end{array}$ & $\begin{array}{l}\text { Mengenai pembagian } \\
\text { admin untuk masing - }\end{array}$ & $\begin{array}{lll}\text { Perlu adanya } & \text { koordinasi } \\
\text { kembali } & \text { dengan pusat untuk }\end{array}$ \\
\hline
\end{tabular}


Vol. 2, No. 1, March 2020

p-ISSN: 2656-5935 http://journal-isi.org/index.php/isi e-ISSN: 2656-4882

\begin{tabular}{|l|l|l|l|}
\hline & $\begin{array}{l}\text { masing menu pada } \\
\text { aplikasi yang belum } \\
\text { sepenuhnya } \\
\text { diimplementasikan } \\
\text { sesuai dengan yang } \\
\text { direncanakan } \\
\text { sebelumnya. }\end{array}$ & $\begin{array}{l}\text { pengelola aplikasi tidak } \\
\text { dibebankan pada satu admin } \\
\text { saja. }\end{array}$ \\
\hline
\end{tabular}

\section{KESIMPULAN}

Berdasarkan hasil analisis data dari analisis manajemen layanan TI pada Aplikasi Salatigaku menggunakan ITIL V3 domain service operation, maka dapat diketahui bahwa sistemlayanan tersebutsudah cukup baik. Namun masih ditemukankendala yang timbul pada beberapa proses seperti incident management, problem management dan access management.Dapat disimpulkan bahwa DISKOMINFO belum sepenuhnya menerapkan ketiga proses sub domain dalam mengelola layanan.Hal ini yang menyebabkan akses layanan TI tidak dapat berjalan secara optimal dan dapat mengganggu kegiatan operasional layanan.Melihat dari temuan yang didapati, DISKOMINFO juga telah menyadari bahwa beberapa poin tersebut masih menjadi kekurangan mereka. Sehingga dengan adanya penelitian ini, rekomendasi yang diberikan dapat memperbaiki beberapa poin yang telah menjadi kelemahan dari layanan Salatigaku serta dapat meningkatkan efektifitas dan efisiensi kinerja layanan TI.

\section{DAFTAR PUSTAKA}

[1] J. Iden and T. R. Eikebrokk, "Implementing IT Service Management: A systematic," International Journal of Information Management, vol. 33, p. 512- 523, 2013.

[2] D. Galup, R. Dattero, J. J. Quan and S. Conger, "An Overview of IT Service Management," Communications Of The Acm, vol. Vol. 52, 2009.

[3] Diskominfo, Peraturan Walikota Salatiga No. 38 Tahun 2016 tentang Kedudukan, Susunan Organisasi, Tugas dan Fungsi serta Tata Kerja Dinas Komunikasi dan Informatika,, 2016.

[4] itSMF, An Introductory Overview of ITIL V3, IT Service Management Forum Limited, 2007.

[5] A. F. Wijaya, M. N. Sitokdana and P. Hapsari, "Analysis of Information Technology Service Management using the ITIL V3 Domain Service 
Operation Framework on SIMDA (Case Study: Boyolali Regency Inspectorate," Internasional Conference of Organizational Innovation (ICOI), 2019.

[6] A. Soukotta and A. D. Manuputty, "Analisis Kualitas Manajemen Layanan Teknologi Informasi Menggunakan Framework Information Technology Infrastructure Library V3 Domain Service Operation (Studi Kasus: Badan Pelayanan Perizinan," Fakultas Teknologi Informasi, Universitas Kristen Satya Wacana, 2017.

[7] P. J. Sahuleka and A. D. Manuputty, "Analisis Kualitas Layanan Teknologi Informasi dengan Menggunakan Framework Information Technology Infrastructure Library Version 3 (ITIL V.3) Service Operation (Studi Kasus PT. PLN (Persero) Distribusi Jateng \& DIY).," Fakultas Teknologi Informasi, Universitas Kristen Satya Wacana, 2016. 